\title{
Comparative Study between Sliding Mode Control and the Vectorial Control of a Brushless doubly fed induction generator
}

\author{
Oussama Moussa ${ }^{1}$, Rachid Abdessemed ${ }^{1}$, Said Benaggoune ${ }^{1}$, Hani Benguesmia ${ }^{2}$ \\ ${ }^{1}$ Department of Electrical Engineering, Faculty of Technology, University of Batna 2, ALGERIA \\ ${ }^{2}$ Department of Electrical Engineering, Faculty of Technology, University of M'sila, ALGERIA
}

ouskador@gmail.com

\begin{abstract}
Brushless doubly fed induction generators (BDFIG) show commercial promise for wind-power generation due to their lower capital and operational costs and higher reliability as compared with doubly fed induction generators. This paper proposes a robust sliding mode control of grid-connected brushless doubly fed induction generator (BDFIG). The developed algorithm is based on the decoupling control by using oriented grid flux vector control strategy. The decoupling of the active and the reactive stator powers insures an optimal performance of the BDFIG at the sub-synchronous region. The stator of this machine incorporates two sets of three phase windings with different number of poles, power winding $(\mathrm{PW})$ and control winding $(\mathrm{CW})$. The proposed method is tested with the Matlab/Simulink software. Simulation results illustrate the performances and the feasibility of the designed control.
\end{abstract}

Keywords: Brushless doubly fed induction generator (BDFIG), Vector control, Sliding mode control (SMC), Active and reactive power.

Received: 15/11/2018 - Accepted: 17/12/2018

\section{Introduction}

Brushless doubly fed induction generators (BDFIG) remise significant advantages for wind-power generation. The absence of a brush gear increases the reliability of the device and requires less maintenance cost [1]. This configuration is of great importance for offshore and difficult-to-reach installations. Moreover, the BDFIG manufacturing cost is very less compared to the doubly fed induction generator [2] [3]. This fact is due to the absence of slip-ring system and the simple structure of the rotor winding. Recently, research efforts are directed towards eliminating the slip rings and brushes while maintaining the benefits of DFIG..

In literature, several BDFIG scalar control algorithms are proposed. For instance, it is shown that the open-loop control, the closed-loop frequency control and the phase angle control can stabilize the machine over a wide speed range. However, the vector control (VC) methods, also known as field-oriented control, give better dynamic performance [3] [4]. This last can be implemented with a conventional proportional plus integral (PI) controller [57]. In general these control proposals are intrinsically based on Taylor's linearization of the system dynamic model around a particular operational point. Therefore, the tuning of the controller is only valid in a restricted operational area. On the other hand, these controllers are not robust against parameter variations, model uncertainties and external perturbations, and can present an asymptotic convergence. Their main advantage lies in their relatively simple implementation with a rather low computational cost.

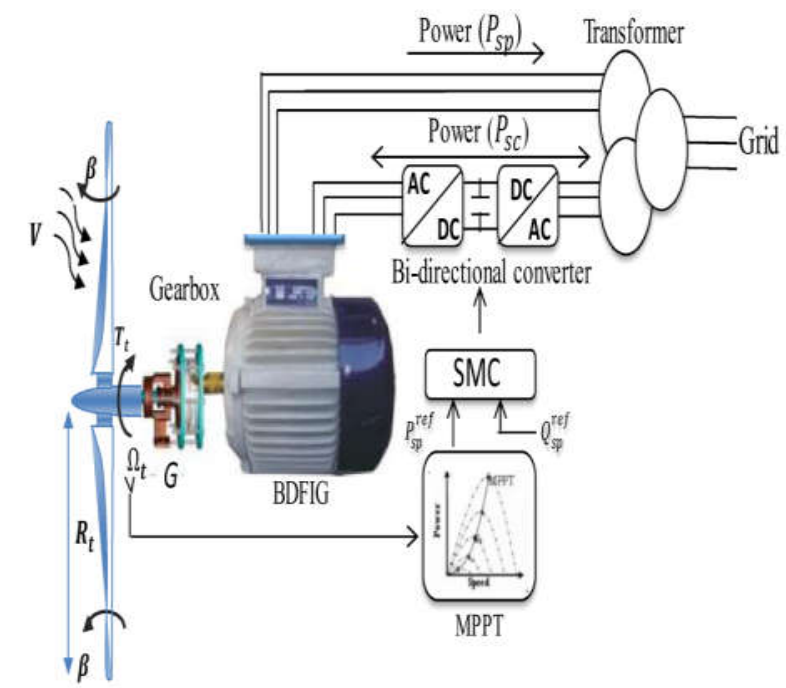

Figure 1. Schematic diagram of BDFIG wind power generation system 
More accurate methods are developed based on different nonlinear control techniques.

For instance, neural networks [8], feedback linearization [9], variable structure control [10], fuzzy logic control [11, 12], combinations of some previous techniques [13], and other nonlinear approaches are possible design alternatives.

Despite the recognized advantage of using nonlinear controllers to cope with nonlinear systems, many of these techniques produce control laws with a rather high computational burden. These calculi commonly depend on the system states and on several model parameters having the secondary effect of reducing the control robustness. This paper a new variable structure controller using a dynamic model with a unified reference fame based on the power winding flux oriented controlled is proposed, the sliding mode control (SMC) is conception for the power loop of the outer loop associated to power flux oriented vector control scheme.

\section{Theory of Operation}

The brushless doubly fed machine (BDFIG), also known as a self-cascaded machine. As shown in Fig. 1, the stator of this machine incorporates two sets of three phase windings with different number of poles.

The first one, called power winding (PW), is connected directly to the grid and handles most of the machine power. The other one, called control winding $(\mathrm{CW})$, is connected via a bi-directional converter to the grid and handles a small percentage of machine power. The rotor of the BDFIG carries special design cage (Sarasola 2008; Williamson et al. 1997).

Typically the two stator supplies are of different frequencies, one a fixed frequency supply connected to the grid via switch, and the other a variable frequency supply derived from a power electronic frequency converter (inverter), as illustrated in Fig. 1. The BDFIG can be operated in several modes, including the synchronous (doubly fed) mode, cascade mode, and induction mode (Shao et al. 2009). The synchronous mode is the most desirable mode in which the shaft speed is independent of the torque exerted on the machine. This is achieved when the following two relations are satisfied (Williamson et al. 1997).

$$
\begin{aligned}
& \omega_{r}=\frac{\omega_{s c} \pm \omega_{s p}}{P_{c}+P_{p}} \\
& N_{r}=P_{c}+P_{p}
\end{aligned}
$$

Where $\mathrm{w}_{\mathrm{sp}}$ and $\mathrm{w}_{\mathrm{sc}}$ are the electrical angular velocities of the $\mathrm{PW}$ and $\mathrm{CW}$ voltages, and $\mathrm{wr}$ is the rotor angular speed. $\mathrm{Pp}$ and $\mathrm{Pc}$ are the number of pole pairs of $\mathrm{PW}$ and $C W$ respectively, in our case $P_{p}=3$ and $P_{c}=1$ and $N_{r}$ is the number of rotor bars. The \pm sign accounts for the case which the $\mathrm{CW}$ is excited in positive or negative phase sequence as illustrated in Fig. 2.

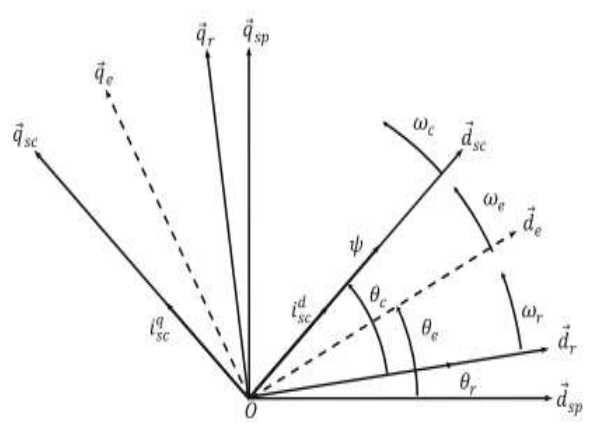

Figure 2. Different reference frame in BDFIG

If the conditions stated in Eqs (1) and (2) are satisfied, then a cross coupling between the two stator fields will occurs via the rotor, and hence a nonzero average torque will be produced. This mode of operation the BDFIG is called "Synchronous Mode". To avoid the direct mutual coupling between the two stator field windings their number of poles should be different (Sarasola 2008)

\section{Mathematical Model of BDFIG}

The BDFIG equations obtained in the $(\mathrm{d}, \mathrm{q})$ reference frame depicted in Fig. 2, that rotates synchronously with the power winding stator flux by angular speed of $\mathrm{W}_{\mathrm{sp}}[15][16]$ can be expressed as

$$
\begin{aligned}
& V_{s p}=R_{s p} I_{s p}+\frac{d}{d t} \Phi_{s p}+j \omega_{s p} \Phi_{s p} \\
& V_{s c}=R_{s c} I_{s c}+\frac{d}{d t} \Phi_{c}+j \omega_{s c} \Phi_{s c} \\
& V_{r}=R_{r} I_{r}+\frac{d}{d t} \Phi_{r}+j \omega_{r} \Phi_{r} \\
& \Phi_{s p}=L_{s p} I_{s p}+M_{p} I_{r} \\
& \Phi_{s c}=L_{s c} I_{s c}+M_{c} I_{r} \\
& \Phi_{r}=L_{r} I_{r}+M_{c} I_{s c}+M_{p} I_{s p} \\
& T_{e m}=\frac{3}{2} P_{p} \operatorname{Im}\left\{\Phi_{s p}^{*} \cdot I_{s p}\right\}+\frac{3}{2} P_{c} \operatorname{Im}\left\{\Phi_{s c} \cdot I_{s c}^{*}\right\}
\end{aligned}
$$

Where: Vsp, Vsc and $\mathrm{Vr}$ are the $\mathrm{PW}, \mathrm{CW}$ and rotor winding voltage vector respectively.

$\mathrm{R}_{\mathrm{sp}}, \mathrm{R}_{\mathrm{sc}}$ and $\mathrm{R}_{\mathrm{r}}$ the PW, CW and rotor resistances. $\mathrm{L}_{\mathrm{sp}}$, $\mathrm{L}_{\mathrm{sc}}$ and $\mathrm{L}_{\mathrm{r}}$ are the self-inductances of the PW, CW and rotor winding respectively.

$\mathrm{M}_{\mathrm{p}}$ is the mutual inductance between the PW and the rotor.

$\mathrm{M}_{\mathrm{c}}$ is the mutual inductance between the CW and the rotor. 
$\Phi_{\text {sp }}, \Phi_{\text {sc }}$ and $\Phi_{\mathrm{r}}$ are the PW, CW and rotor flux space vector respectively.

The powers winding active and reactive power are expressed as:

$$
\begin{aligned}
& P_{s p}=\frac{3}{2}\left(V_{s p}^{d} I_{s p}^{d}+V_{s p}^{q} I_{s p}^{q}\right) \\
& Q_{s p}=\frac{3}{2}\left(V_{s p}^{q} I_{s p}^{d}-V_{s p}^{d} I_{s p}^{d}\right)
\end{aligned}
$$

Current-flux equations:

$$
\begin{aligned}
& I_{s p}=\frac{\Phi_{s p}-M_{p} I_{r}^{d}}{L_{s p}} \\
& I_{r}=\frac{\Phi_{r}-M_{p} I_{s p}-M_{c} I_{s c}}{L_{r}}
\end{aligned}
$$

Equation (9) is obtained by replacing Eq. (8) in Eq. (7):

$$
\begin{aligned}
& I_{s p}=\frac{L_{r}}{L_{s p} L_{r}-M_{p}^{2}} \Phi_{s p}-\frac{M_{p}}{L_{s p} L_{r}-M_{p}^{2}} \Phi_{r} \\
& +\frac{M_{c} M_{p}}{L_{s p} L_{r}-M_{p}^{2}} I_{s c}
\end{aligned}
$$

The Eq. (10) is obtained by substituting Eq. (9) in Eqs.(5) and (6):

$$
\left\{\begin{array}{l}
P_{s p}=\frac{3}{2} V_{s p}\left(\delta_{5} \Phi_{s p}^{q}-\delta_{4} \Phi_{r}^{q}+\delta_{3} I_{s c}^{q}\right) \\
Q_{s p}=\frac{3}{2} V_{s p}\left(\delta_{5} \Phi_{s p}^{d}-\delta_{4} \Phi_{r}^{d}+\delta_{3} I_{s c}^{d}\right)
\end{array}\right.
$$

With;

$$
\begin{aligned}
& \delta_{1}=\frac{M_{c} L_{s p}}{L_{s p} L_{r}-M_{p}^{2}}, \delta_{2}=L_{s c}-\frac{M_{c}^{2} L_{s p}}{L_{s p} L_{r}-M_{p}^{2}}, \delta_{3}=\frac{M_{c} M_{p}}{L_{s p} L_{r}-M_{p}^{2}} \\
& \delta_{4}=\frac{M_{p}}{L_{s p} L_{r}-M_{p}^{2}}, \delta_{5}=\frac{L_{r}}{L_{s p} L_{r}-M_{p}^{2}}
\end{aligned}
$$

From Eqs. (3-10), the dynamic relation between the CW current and the voltage in the $\mathrm{d}-\mathrm{q}$ axis (Vsc and Isc) is given as follows:

$$
\left\{\begin{array}{l}
V_{s c}^{q}=R_{s c} I_{s c}^{q}+\left(\frac{d}{d t}\left(\delta_{1} \Phi_{r}^{q}+\delta_{2} I_{s c}^{q}\right)+\omega_{s c}\left(\delta_{1} \Phi_{r}^{d}+\delta_{2} I_{s c}^{d}-\delta_{3} \Phi_{s p}^{d}\right)\right) \\
V_{s c}^{d}=R_{s c} I_{s c}^{d}+\left(\frac{d}{d t}\left(\delta_{1} \Phi_{r}^{d}+\delta_{2} I_{s c}^{d}\right)-\omega_{s c}\left(\delta_{1} \Phi_{r}^{q}+\delta_{2} I_{s c}^{q}-\delta_{3} \Phi_{s p}^{q}\right)\right)
\end{array}\right.
$$

\section{Power decoupled control}

The target of the vector control is to achieve independent control of the active and reactive power of the PW. This can be fulfilled using the vector control technique described in the following section.

The model of the BDFG is derived in the PW synchronously rotating $\mathrm{d}-\mathrm{q}$ reference fame with the $\mathrm{d}$ axis aligned with the PW flux.

Accordingly $\Phi_{s p}^{d}=\left|\Phi_{s p}\right|$. But there is no component in the q-axis

$$
\left\{\begin{array}{l}
\Phi_{s p}^{d}=\left|\Phi_{s p}\right| \\
\Phi_{s p}^{q}=0
\end{array}\right.
$$

To simplify calculations, let us assume that the resistance of the stator winding $R_{s p}$ is ignored, the voltage equations of the stator windings (PW) can be simplified in steady state as following [17]:

$$
\left\{\begin{array}{l}
V_{s p}^{d}=0 \\
V_{s p}^{q}=V_{s p}
\end{array}\right.
$$

Replacing Eqs. (13) and (12) in Eq. (10), the power expressions become:

$$
\left\{\begin{array}{l}
P_{s p}=\frac{3}{2} V_{s p}^{q}\left(-\delta_{4} \Phi_{r}^{q}+\delta_{3} I_{s c}^{q}\right) \\
Q_{s p}=\frac{3}{2} V_{s p}^{q}\left(\delta_{5} \Phi_{s p}^{d}-\delta_{4} \Phi_{r}^{d}+\delta_{3} I_{s c}^{d}\right)
\end{array}\right.
$$

\section{Sliding Mode Power Controller Design}

Sliding Mode Controller (SMC) is a powerful nonlinear controller which has been analyzed by many researchers especially in recent years [18, 19]. This method forces the system to slide along a predesigned sliding mode surface and alters the dynamic of system by using a discontinuous control signal [20]. This last allows the switch at any time between the different structures. Thus, it combines the useful properties of each of these structures in order to obtain the desired system behavior. In fact, the Lyapunov like stability condition guarantees that the distance between the system state and the surface decreases along all system trajectories and constrains the trajectories to move toward the sliding surface [21]. The advantages of the sliding mode controller can be summarized as follows [22]:

Fast response with no overshoot.

$>$ No steady state error.

> Robustness, stability in a closed loop environment, insensitivity to parameter variations and load disturbances. 
One considers the system described by the following state space equation:

$$
[\dot{X}]=[A][X]+[B][U]
$$

With, $[X] \in R^{n}$ is the state vector $[U] \in R^{m}$ is the control input vector; $[A]$ and $[B]$ are system parameter matrices.

The first phase of the control design consists of choosing the number of the switching surfaces $s(x)$. Generally this number is equal the dimension of the control vector $[U]$. In order to ensure to convergence of the state variable to its reference value $X^{\text {ref }},[23]$ proposes a general function of the switching surface:

$$
s(x)=\left(\frac{d}{d t}+\lambda\right)^{r-1} e(x)
$$

Where $\lambda$ is a strictly positive constant.

Ensure controllability; $e(x)=X^{\text {ref }}-X$ is the error variable. The second phase consists to find the control law which meets the suiciency conditions for the existence and reachability of a sliding mode such as [24]

$$
\dot{s}(x) s(x) \prec 0
$$

Intuitively, the existence of a sliding mode on the sliding surface implies stability of the system. One of the possible solutions is given by:

$$
U(t)=U_{e q}+\Delta U
$$

$\mathrm{U}_{\mathrm{eq}}$ is the so-called equivalent control. It plays the feedback linearization role is the solution of

$$
\begin{gathered}
\dot{s}(x)=\frac{d s}{d t}=\frac{\partial s}{\partial x} \frac{\partial x}{\partial t} \\
\dot{s}(x)=\frac{d s}{d t}=\frac{\partial s}{\partial x}\left\{[A][X]+[B] U_{e q}\right\}+\frac{\partial s}{\partial t}[B] \Delta U
\end{gathered}
$$

During the sliding mode, the $\Delta U$ is equal zero, then $\mathrm{U}_{\mathrm{eq}}$ is

$$
U_{e q}=-\left\{\frac{\partial s}{\partial X}[B]\right\}^{-1}\left\{\frac{\partial s}{\partial X}[A][B]\right\}
$$

With: $\frac{\partial s}{\partial X}[B] \neq 0$

During the convergence mode, the $\Delta U \neq 0$ Substituting (21) in to (20), yields

$$
\dot{s}(x)=\frac{\partial s}{\partial X}[B] \Delta U
$$

Substituting (22) in to (17), obtain:

$$
s(x) \frac{\partial s}{\partial X}[B] \Delta U \prec 0
$$

So that the state trajectory is attracted toward the switching surface $s(x)=0$.

A commonly used from of $\Delta U$ is a constant relay control.

$$
\Delta U=k_{x} \operatorname{sign} s(x)
$$

$\operatorname{sign} s(x)$ : is a sign function, which is defined as:

$$
\operatorname{sign} s(x)=\left\{\begin{array}{lll}
-1 & \text { if } & s(x) \prec 0 \\
+1 & \text { if } & s(x) \succ 0
\end{array}\right.
$$

Where $k_{x}$ determine the ability of overcoming the chattering. In order to reduce the chattering phenomenon caused by the discontinuous nature of the controller, a smooth function is used in some neighborhood of the sliding surface.

\section{VI.Sliding Mode Control of BDGIF}

In this section, the sliding surfaces are defined based on the active and the reactive power references given in the Eq. (14). The main objective of this design is to independently control the active and reactive generated powers.

\section{A. Choice of the sliding surfaces}

In this work, two sliding surfaces are used and taken as follows since a first order is defined as:

$$
\begin{aligned}
& s\left(P_{s p}^{r e f}-P_{s p}\right) \\
& s\left(Q_{s p}^{r e f}-Q_{s p}\right)
\end{aligned}
$$

Where $P_{s p}^{r e f}$ and $Q_{s p}^{r e f}$ are the expected active and reactive power reference.

\section{B. Conditions of convergence}

To insure the convergence of selected variables towards the references, the two slip surfaces need to be null as following:

$$
\left\{\begin{array} { l } 
{ s ( P _ { s p } ) = 0 } \\
{ s ( Q _ { s p } ) = 0 }
\end{array} \Rightarrow \left\{\begin{array}{l}
\frac{d}{d t}\left(P_{s p}^{r e f}-P_{s p}\right)=0 \\
\frac{d}{d t}\left(Q_{s p}^{r e f}-Q_{s p}\right)=0
\end{array}\right.\right.
$$

The realization of a sliding mode control relies on the Lyaponov attractively $(s(x) s(x) \prec 0)$ and the surface time invariance ${ }_{s(x)}=0$

\section{Development of the control laws}

The algorithm of control is defined by the relation: 


$$
\begin{aligned}
& V_{s c}^{d}=V_{s c}^{d-e q}+V_{s c}^{d-a t t r} \\
& V_{s c}^{q}=V_{s c}^{q-e q}+V_{s c}^{q-a t t r}
\end{aligned}
$$

$V_{s c}^{d}, V_{s c}^{q}:$ is the control vector.

$V_{s c}^{d-e q}, V_{s c}^{q-e q}$ : is the equivalent control vector. $V_{s c}^{d-a t t r}, V_{s c}^{q-a t t r}:$ is the switching part of the control.

To control the power one takes $r=1$, the expression of the surface has as a form:

$$
\left\{\begin{array}{l}
s\left(P_{s p}\right)=\left(P_{s p}^{r e f}-P_{s p}\right) \\
s\left(Q_{s p}\right)=\left(Q_{s p}^{r e f}-Q_{s p}\right)
\end{array}\right.
$$

The derivative of surface:

$$
\left\{\begin{array}{l}
\frac{d}{d t} s(P)=\left(\dot{P}_{s p}-\dot{P}_{s p}\right)=0 \\
\frac{d}{d t} s(Q)=\left(\dot{Q}_{s p}^{r e f}-\dot{Q}_{s p}\right)=0
\end{array}\right.
$$

One draws the expression. From $\dot{P}_{s p}^{r e f}, \dot{P}_{s p}, \dot{Q}_{s p}^{r e f}, \dot{Q}_{s p}$

$$
\begin{aligned}
& \dot{S}\left(P_{s p}\right)=\left[\dot{P}_{s p}^{r e f}-\frac{3}{2} V_{s p}^{q}\left(-\delta_{4} \dot{\Phi}_{r}^{q}+\delta_{3} \dot{I}_{s c}^{q}\right)\right] \\
& \dot{s}\left(Q_{s p}\right)=\left[\dot{Q}_{s p}^{r e f}-\frac{3}{2} V_{s p}^{q}\left(\delta_{5} \dot{\Phi}_{s p}^{d}-\delta_{4} \dot{\Phi}_{r}^{d}+\delta_{3} \dot{I}_{s c}^{d}\right)\right]
\end{aligned}
$$

Substituting the current expression $\left(I_{s c}^{d}, I_{s c}^{q}\right)$ into (31-32), obtains:

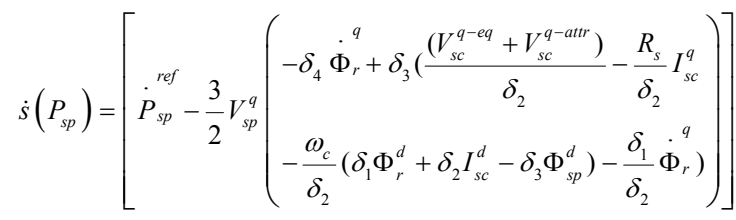

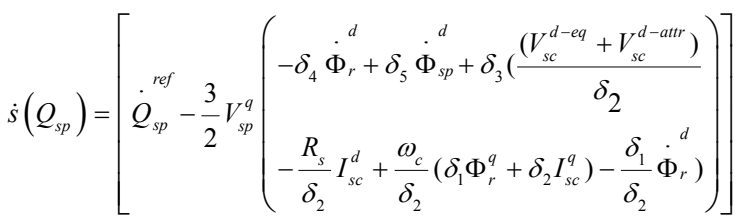

The equivalent control winding current vector $V_{s c}^{q}$ can express by:

$$
\begin{aligned}
& V_{s c}^{d-e q}=\frac{\delta_{2}}{\delta_{3}}\left[\frac{\dot{\Phi}_{s p}^{r e f}}{1.5 V_{s p}^{q}}+\delta_{4} \dot{\Phi}_{r}^{d}\right]+R_{s} I_{s c}^{d}-\omega_{c}\left(\delta_{1} \Phi_{r}^{q}+\delta_{2} I_{s c}^{q}\right)+\delta_{1} \dot{\Phi}_{r}^{d} \\
& V_{s c}^{q-e q}=\frac{\delta_{2}}{\delta_{3}}\left[\frac{\dot{P}_{s p}^{r e f}}{1.5 V_{s p}^{q}}+\delta_{4} \dot{\Phi}_{r}^{q}\right]+R_{s} I_{s c}^{q}+\omega_{c}\left(\delta_{1} \Phi_{r}^{d}+\delta_{2} I_{s c}^{d}-\delta_{3} \Phi_{s p}^{d}\right)+\delta_{1} \dot{\Phi}_{r}^{q}(36)
\end{aligned}
$$

$V_{s c}^{a t t r}$ is the Sign function defined by:

$$
\begin{aligned}
& V_{s c}^{d-a t t r}=k_{d} \operatorname{sign}\left(s\left(Q_{s p}\right)\right) \\
& V_{s c}^{q-a t t r}=k_{q} \operatorname{sign}\left(s\left(P_{s p}\right)\right)
\end{aligned}
$$

Where $k_{d}, k_{q}$ determine the ability of overcoming the chattering.

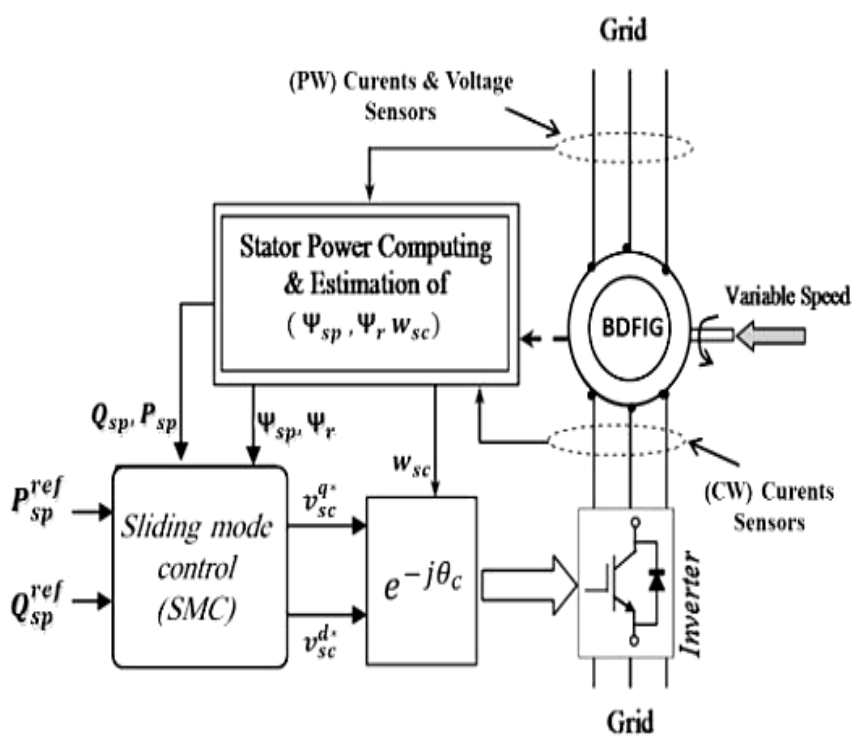

Figure 3. Sliding mode control block diagram of BDFIG.

The SMC control is conception for the power loop of the outer loop associated to power flux oriented vector control scheme, to further enhance the robustness of the system path as shown in figure 3

\section{Simulation Results}

To confirm the electiveness of the proposed SMC algorithm for BDFIG it is simulated in the environment of Matlab/Simulink to investigate the dynamic performance of the (BDFIG.) The parameters of the BDFIG are given in the appendix (Table I) [13].

Figure 4 are the simulation results for active and reactive power response in case of fixed speed operation when traditional PI controller (Fig. 4(a)) and sliding mode control (Fig. 4(b) ) is applied. In this case study, simulation results show clearly the improvement of active and reactive power demand obtained by applying sliding mode control in term of time response and good reference tracking accuracy than those obtained using traditional PI regulator. We notice here, in case of step change, that the sliding mode controller transient responses of both active and reactive powers present no overshoot whereas the steady state error is close to zero. 

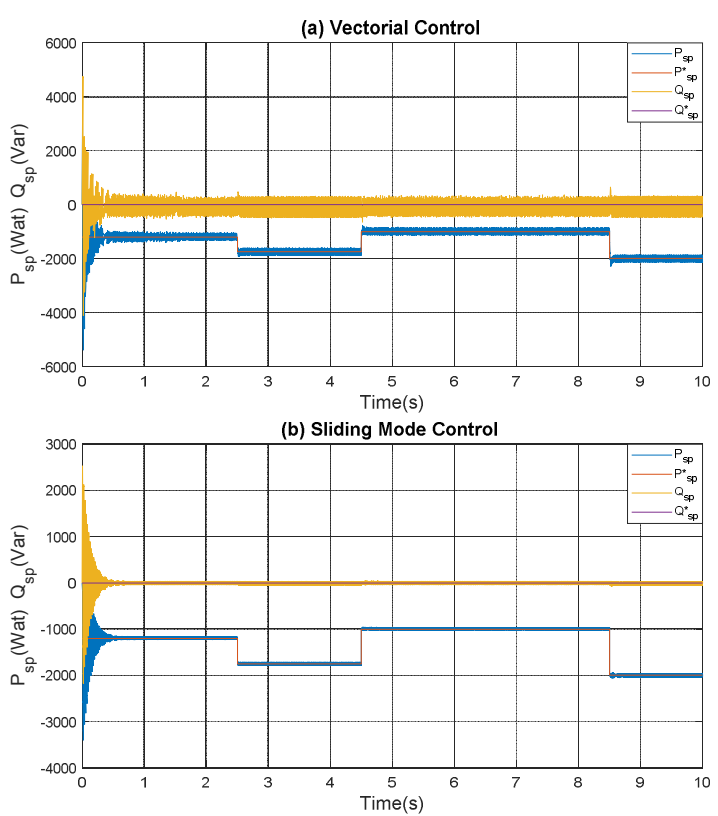

Figure 4. Active and reactive power response of Stator (PW)

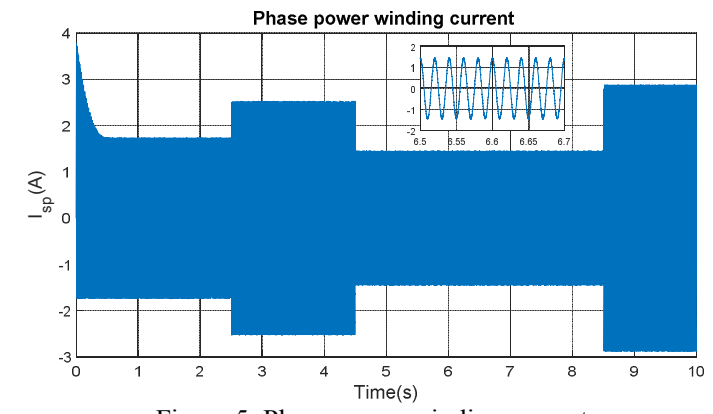

Figure 5. Phase power winding current

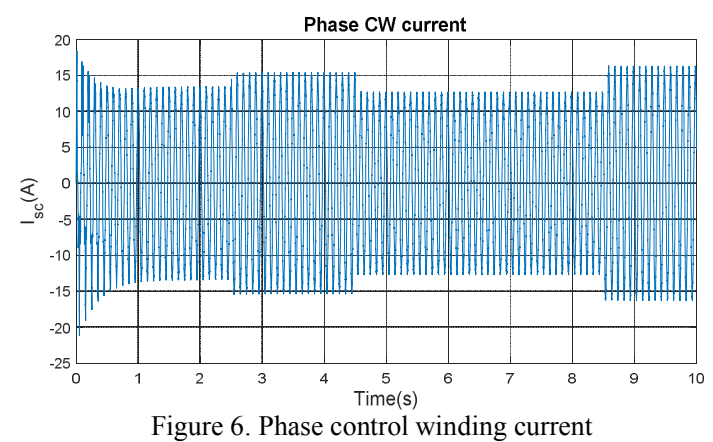

The frequency and amplitude of the control winding current both change during the period of the active and reactive power variation, the frequency of power winding current is constants accorder to power frequency of the grid with amplitude change when the reference of the active power is modified as shown in Fig. 5and 6.

\section{Conclusion}

This paper presents a comparative study on the performance of two control strategies; vector and sliding mode controller applied on a BDFIG wind turbines when operated in power regulation mode. This last, can control the stator (PW) active and reactive powers independently with desired performances of stability and robustness. Therefore, the obtained results demonstrate the efficiency of the adopted control structure. It can be concluded that the proposed BDFIG system control is an interesting solution in the wind energy conversion systems.

\section{Appendix}

Table. I

Electrical parameters of prototype BDFIG for simulation

\begin{tabular}{|l|l|l|l|}
\cline { 2 - 3 } \multicolumn{1}{c|}{} & $\begin{array}{l}\text { Power winding } \\
(\mathrm{PW})\end{array}$ & $\begin{array}{l}\text { Control } \\
\text { Winding }(\mathrm{CW})\end{array}$ & Rotor \\
\hline Resistance $(\Omega)$ & $\mathrm{R}_{\mathrm{sp}}=1.732$ & $\mathrm{R}_{\mathrm{sc}}=1.079$ & $\mathrm{R}_{\mathrm{r}}=0.473$ \\
\hline $\begin{array}{l}\text { Self inductance } \\
(\mathrm{mH})\end{array}$ & $\mathrm{L}_{\mathrm{sp}}=714.8$ & $\mathrm{~L}_{\mathrm{sc}}=121.7$ & $\mathrm{~L}_{\mathrm{r}}=132.6$ \\
\hline $\begin{array}{l}\text { Mutual } \\
\text { inductance }(\mathrm{mH})\end{array}$ & $\mathrm{M}_{\mathrm{p}}=242.1$ & $\mathrm{M}_{\mathrm{c}}=59.8$ & \\
\hline Pole pair numbers & $\mathrm{P}_{\mathrm{p}}=3$ & $\mathrm{P}_{\mathrm{c}}=1$ & \\
\hline
\end{tabular}

\section{References}

[1] P. Farrokh, M. Jalalifar, Robust Speed Sensorless control of doubly-fed induction machine based on input-output feed back linearization control using a sliding-mode observer, International Proceedings of the IEEE international conference on power electronics, drives and energy systems, 2006. pp. 1-5,

[2] R. A. McMahon, X. Wang, E. Abdi, P. J. Tavner, P. C. Roberts, and M. Jagiela, The BDFM as a generator in wind turbines, in Proc. $12^{\text {th }}$ Int. Power Electron. Motion Control Conf, 2008. pp. 1859-1865,

[3] S. Shao, E Abdi, F Barati, R. Mcmahon, flux-oriented vector control for brushless doubly fed induction generator, IEEE Transactions on Industrial Electronics, Vol. 56, no. 10, 2009. pp. 4220-4228,

[4] R. Mcmahon, X. Wang, E Abdi, M. Jagiela, The BDFM as a generator in wind turbines, In: Proceedings ofthe 12th International Conference on Power Electronics and Motion Control, 2006. pp. 1859-1865,

[5] K. Protsenko, D. Xu, Modeling and control of brushless doubly-fed induction generators in wind energy applications, IEEE Transactions on Power Electronics, Vol. 23, no. 3, pp. 1191-1197, 2008.

[6] I. Sarasola, Robust control of doubly fed induction machine by the stator power generation applications at variable speed. Dissertation for the Doctoral Degree, Basque: University of Mondragon, 2008.

[7] S. Williamson, S. Ferreira, A. K. Wallace, Generalized theory of the brushless doubly-fed machine 2. Model verification and performance, IEEE Proceedings-Electric Power Application, Vol. 44, no. 2, 1997. pp. 111-122,

[8] J. Poza, E. Oyarbide, M. Rodriguez, Unified reference framed model of the brushless doubly fed machine, IEEE Proceedings-Electric Power Application, Vol. 153, no.5, 2006. pp. 726-734,

[9] A. Tamaarat, A. Benakcha, Performance of PI controller for control of active and reactive power in DFIG operating in a grid-connected variable speed wind energy conversion system, Frontiers in Energy, Vol. 8, no.3, 2014. pp. 371378 , 
[10] O. Soares, H. Goncalves, A. Martins, A. Carvalho, Nonlinear control of the doubly fed induction generator in wind power systems. Renewable Energy, Vol.35, no. 8, 2010. pp. 1662-1670,

[11] A. Dida, and D. B. Attous, Doubly-fed induction generator drive based WECS using fuzzy logic controller, Frontiers in Energy, Vol. 9, no. 3, 2015. pp. 272-281,

[12] B. Boukhezzar, and H. Siguerdidjane, Nonlinear control with wind estimation of a DFIG variable speed wind turbine for power capture optimization, Energy Conversion and Management, Vol. 50, no.4, 2009. pp. 885-892,

[13] M. A. Mahboub, and S. Drid, Sliding mode control of a Brushless doublyfed induction generator, In Proceedings of

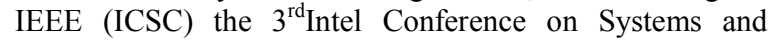
Control, 2013.pp. 308-313,

[14] R. Yazdapanpanah, G. R. Markadeh, Nonlinear torqueand stator flux controller for induction motor drive based onadaptive input-output feedback linearization and sliding mode control, Energy Conversion and Management, Vol. 49, no. 4, 2008. pp. 541-550,

[15] R. McMahon, X. Wang, E Abdi, P. Tavner, M. Jagiela, The BDFM as a generator in wind turbines, In Proceedings of 12th international conference on power electron, 2006.pp.1859-1865,

[16] K. Protsenko, D. Xu, Modeling and control of brushless doubly fed induction generators in wind energy applications, IEEE Trans Power Electron, Vol.23, no.3, 2008. pp. 1191-1197,

[17] T. Mesbahi, A. Ouari, T. Ghennam, E. Berkouk, N. Mesbahi, Ahybrid wind energy conversion system/active filter for nonlinear conditions, Int J Syst Assur Eng Manag, Vol. 6, no. 4, 2011.

[18] B. Beltran, M. Benbouzid, T. Ahmed-Ali, H. Manfel, DFIG based wind turbine robust control using high-order sliding modes and a high gain observer, International Review on Modelling and Simulations, Vol.4, no.3, 2011. pp. 1148-1155,

[19] A. Abdellah, A. Abdelhafid, R. Mostafa, Combining sliding mode and linear quadratic regulator to control the inverted pendulum, International Review of Automatic Control, Vol. 6, no.1, 2013. pp. 69-76,

[20] F. Yong, C. Bing, Y. Xinghuo, and Y. Yongmin, Terminal sliding mode control of induction generator for wind energy conversion systems, 38th Annual Conference on IEEE Industrial Electronics Society, 2012. pp.4741-4746,

[21] G. Andrade, D. Pangano, J. Lvarez, M. Berenguel, Sliding mode control of distributed parameter processes: application to asolar power plant, J Control Autom Electr Syst, Vol. 25, no. 3, 2014. pp.291-302,

[22] F. Benchabane, A. Titouine, O. Beennis, K yahia, D. Taibi, fuzzy sliding mode control for permanent magnetsynchronous motor fed by AC/DC/AC converter, Int J Syst Assur Eng Manag, Vol. 6, no.2, 2013. pp.192-199,

[23] O. Zouaid, L. Nezli, Control with Sliding Mode of a FivePhase Series-Connected Two-asynchronous Motor Drive. International Journal of Energetica (IJECA), Vol.3, Issue 1. 2018.

[24]V. Utkin, Variable stucture systems with sliding modes-a survey, IEEE Trans Automat Control, Vol. 22, no.2, 1977. pp. 212-222, 